Thorax (1975), 30, 344.

\title{
Successful outcome of complications of excision of aortic coarctation
}

\author{
RAHEEM M.A. KHAN and KENNETH BLOOR \\ Department of Thoracic and Cardiovascular Surgery, Manchester Royal Infirmary
}

\begin{abstract}
Khan, R. M. A. and Bloor, K. (1975). Thorax, 30, 344-347. Successful outcome of complications of excision of aortic coarctation. A case is described of a patient who made a complete recovery following unusually serious complications of excision of aortic coarctation. The thoracic aorta was reconstructed successfully using an aortic graft along a course which appears to be short and direct.
\end{abstract}

Crafoord and Nylin (1945) and Gross and Hufnagel (1945) first described the surgical treatment of coarctation of the aorta. The operative mortality of about $5 \%$ appears to be fairly constant in most series (Claggett, Kirklin, and Ellis, 1955; Schuster and Gross, 1962; Karnell, 1968). About one-third of the fatal complications seem to be due directly to damage to easily traumatized vessels or to anastomotic disruptions. The case of a 19-year-old man who had his left subclavian artery, arch of the aorta, and lower thoracic aorta ligated following such complications is described. The continuity was restored successfully by using an aortic graft between the ascending and lower thoracic aorta. For difficult, inaccessible or recurrent aortic coarctations, a course for the graft is described, which appears to be short and direct.

\section{CASE REPORT}

A 19-year-old man was admitted to a regional hospital with an adult type of aortic coarctation. Blood pressure in the right arm was $220 / 120$ $\mathrm{mmHg}$ and in the left arm $200 / 110 \mathrm{mmHg}$. The pulsations in both femoral arteries were feeble. The electrocardiogram showed sinus rhythm and left ventricular hypertrophy.

His coarctation was explored through a left thoracotomy. There was a narrow segment approximately $4 \mathrm{~cm}$ long close to the origin of the left subclavian artery. This was excised and replaced with a length of aortic Teflon graft. Postoperatively the patient bled excessively and went into a state of shock, which necessitated a further thoracotomy on the following day. About 2 litres of blood clots were evacuated and haemostasis was secured along the distal suture line.
Since there was no improvement in the arteria $\stackrel{\Phi}{D}^{2}$ pulsations in the lower limbs, an arch aortograme was carried out. This showed that the proxima anastomosis was about $8 \mathrm{~mm}$ wide. A further ex-응 ploratory thoracotomy was performed one month after the first thoracotomy. There were a fewo blood clots which were removed. The left sub: clavian artery, the arch of the aorta, and the proximal end of the graft were mobilized. The aorta was cross-clamped and the proximal end of 3 the graft was detached. While the distal anasto mosis was being examined, bleeding started fromp. near the aortic cross-clamp. At this stage the kef subclavian artery came off the aortic arch and? had to be clamped and ligated. The aortic cross $\underset{x}{x}$ clamp was replaced more proximally close to the left common carotid artery. During this process. the phrenic and vagus nerves were divided. Byô this time considerable blood loss had taken place? which resulted in cardiac arrest. The blood re은 placement was speeded up, cardiac massage begun, and an intracardiac injection of adrenaline hydrochloride given. This resulted in ventriculan fibrillation, which responded well to a single direct current shock.

In view of the very friable vascular tissue andu the fact that not enough of the aorta was available proximally for a further anastomosis, the situac tion was accepted. The arch of the aorta between the left subclavian and common carotid arteries ${ }^{+}$ was transfixed and ligated and so was the lower thoracic aorta. Following a rather protracted con $\frac{\mathrm{P}}{\mathrm{D}}$ valescence the patient was discharged home a month after the last operation.

He was readmitted three months later for further investigations and assessment. His only 
symptoms were hoarseness of the voice and slight breathlessness on exertion. The blood pressure in the right arm was $230 / 100 \mathrm{mmHg}$ and in the left $150 / 90 \mathrm{mmHg}$. There was no evidence of heart failure. The electrocardiogram showed a considerable increase in left ventricular hypertrophy. The plasma electrolytes and urea levels were within normal limits.

An arch aortogram showed a small 'knuckle' of aorta distal to the origin of the left common carotid artery (Fig. 1). The left subclavian artery was shown to be occluded near its origin. The lower thoracic aorta was also outlined using a Seldinger technique. This showed a totally occluded aorta at the level of the ninth dorsal vertebra. The renal arteries outlined well.

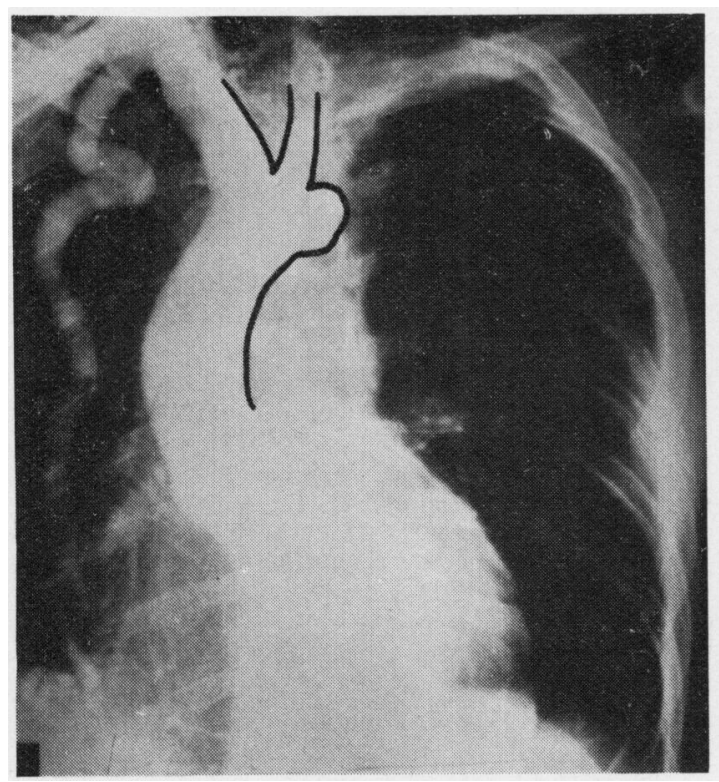

FIG. 1. Cardio-angiographic appearances before reconstructive surgery for the thoracic aorta.

The patient was admitted to Manchester Royal Infirmary about one year after his first operation for assessment and reconstructive surgery. His voice had greatly improved. His only symptom was an occasional headache. Clinical examination revealed an absence of all arterial pulsations in the lower limbs. The blood pressure in the right arm was $240 / 100 \mathrm{mmHg}$ and in the left $160 / 120 \mathrm{mmHg}$.

He was operated on a week later with stand-by cardiopulmonary bypass. The lower thoracic aorta was exposed through the left seventh intercostal space. It was found to be totally occluded at the level of the eighth dorsal vertebra. The proximal aorta was exposed through a mid-sternotomy. The ascending aorta was much narrower than anticipated and it was obviously impossible to place a side clamp without seriously occluding the lumen. Accordingly it was decided to use the cardiopulmonary bypass by cannulating the right atrium and ascending aorta. The patient was cooled to $30^{\circ} \mathrm{C}$. A vent was placed through the apex of the left ventricle. A long woven Teflon graft was used to restore the continuity of the thoracic aorta. The ascending aorta was cross-clamped and an end-toside anastomosis was performed between the medial aspect of the ascending aorta and the graft, using a single layer of continuous stitch of $2 / 0$ Mersilene. A similar procedure was carried out between the lower thoracic aorta and the graft. In its course the graft was placed in front of the main pulmonary artery and left atrial appendix, and finally behind the left ventricle (Fig. 2).

The total duration of ischaemic arrest was 19 minutes. The heart resumed sinus rhythm after the release of the aortic cross-clamp. The femoral and more distal pulses were then palpable. He was discharged home two weeks later following an uneventful recovery. About two and a half years

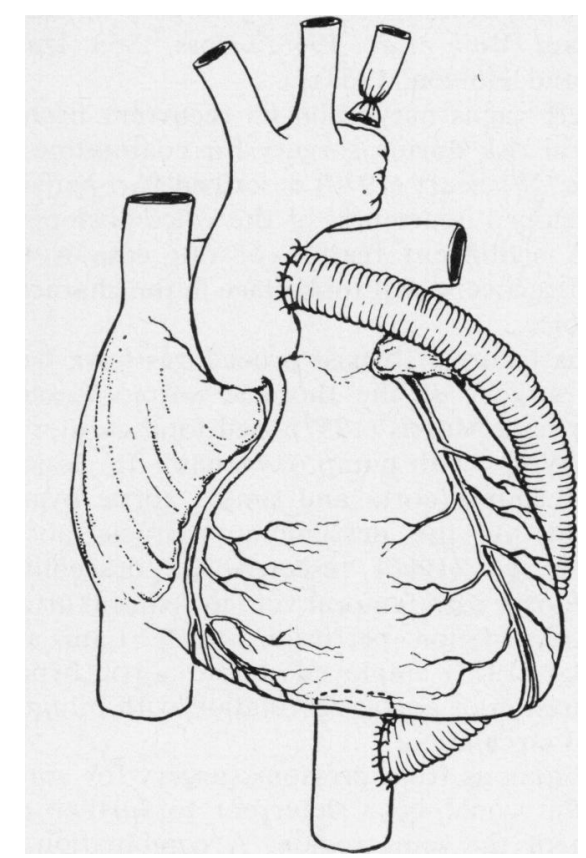

FIG. 2. Diagrammatic representation of the angiocardiographic and operative findings. 
after the reconstructive surgery he was symptomless; all peripheral pulsations were palpable in the limbs, including the left arm. The blood pressure in the right arm was $150 / 100 \mathrm{mmHg}$ and in the left $90 / 65 \mathrm{mmHg}$.

\section{DISCUSSION}

Although excision of aortic coarctation has been practised over the past 30 years, this procedure still carries a significant morbidity and mortality. The main problems appear to be due to easily traumatized vessels or anastomotic disruptions. Braimbridge (1936), reporting 119 cases of coarctation of the aorta, pointed out that careful haemostasis did not prevent five large postoperative haemorrhages, two of which proved to be fatal.

Our patient had friable vessels, and anastomotic disruption took place, resulting in massive blood loss and cardiac arrest. Once the bleeding had been controlled by ligation of the subclavian artery, the adjoining arch of the aorta, and the lower thoracic aorta, he responded well to resuscitative measures.

It is remarkable that in spite of these radical haemostatic procedures there was no evidence of spinal cord or other damage. There are reports of such complications following surgery of aortic coarctation (Bing et al., 1948; Gross, 1953; Izant, Hubay, and Holden, 1953).

The left vagus nerve and its recurrent branch are at real risk during surgery for coarctation of the aorta. Wisheart (1970) described two patients who developed hoarseness of the voice postoperatively. A significant feature of our case is the degree of recovery that took place in the character of the voice.

Various forms of bypass procedures have been used in surgery of the thoracic aorta: Cooley, DeBakey, and Morris (1957) used total cardiopulmonary bypass with pump oxygenator for lesions of the ascending aorta and simple aortic bypass for lesions of the descending thoracic aorta; Neville et al. (1968) resected the descending thoracic aorta with femoral vein to femoral artery bypass oxygenation perfusion; while Lam and Arciniegas (1973) employed simple aortic bypass in the excision of aortic coarctation with minimal collateral circulation.

The adhesions from previous surgery for aortic coarctation could be a deterrent to further exploration of the same region. A combination of mid-sternotomy with left lower thoracotomy is one solution to the problem. Furthermore, this approach provides a short and a direct course for the graft between the ascending and lowe thoracic aorta. In this position it is unlikely to. kink, as it might on the right side or front of the heart. Siderys et al. (1974) constructed a bypass graft from the ascending aorta to the infrarenes abdominal aorta in the management of inaccessible aortic coarctation. We recommend a short. and a direct course for the graft in difficult, in $\vec{\omega}$ accessible or recurrent aortic coarctations.

We wish to thank Mr. J. S. Glennie for allowing ưs to report this case. We should like to thank the Departments of Medical Illustration at the Manchestei Royal Infirmary and Wythenshawe Hospital for th two illustrations.

\section{REFERENCES}

Bing, R. J., Handelsman, J. C., Campbell, J. A. তे Griswold, H. E., and Blalock, A. (1948). The surgical treatment and physiopathology o甲 coarctation of the aorta. Annals of Surgerys 128, 803.

Braimbridge, M. V. (1963). Surgery of the descendin thoracic aorta. Annals of the Royal College of Surgeons of England, 33, 344.

Claggett, O. T., Kirklin, J. W., and Ellis, F. H., J1 (1955). Surgical treatment of coarctation of the aorta. Surgical Clinics of North America, 35 937.

Cooley, D. A., DeBakey, M. E., and Morris, G. CF (1957). Controlled extracorporeal circulation io surgical treatment of aortic aneurysm. Annal of Surgery, 146, 473.

Crafoord, C. and Nylin, G. (1945). Congenita coarctation of the aorta and its surgical treat ment. Journal of Thoracic Surgery, 14, 347.

Gross, R. E. (1953). Coarctation of aorta. Circulation 7, 757.

and Hufnagel, C. A. (1945). Coarctation of the aorta; experimental studies regarding its surgicat. correction. New England Journal of Medicind 0
233, 287.

Izant, R. J., Hubay, C. A., and Holden, W. D. (1953) N A non-suture aortic shunt and experimental study Surgery, 33, 237.

Karnell, J. (1968). Coarctation of the aorta. Circula tion, 38, Supplement, 5, 35.

Lam, C. R. and Arciniegas, E. (1973). Surgicale management of coarctation of the aorta with minimal collateral circulation. Annals of Surgery 178, 693.

Neville, W. E., Cox, W. D., Leininger, B., an $\mathbb{\Phi}$ Pifarré, R. (1968). Resection of the descendin $\$$ thoracic aorta with femoral vein to femorab artery oxygenation perfusion. Journal Thoracic and Cardiovascular Surgery, 56, 39. 
Schuster, S. R. and Gross, R. E. (1962). Surgery of coarctation of the aorta. A review of 500 cases. Journal of Thoracic and Cardiovascular Surgery, 43, 54.

Siderys, H., Graffis, R., Halbrook, H., and Kasbeckar, V. (1974). A technique for management of inaccessible coarctation of the aorta. Journal of Thoracic and Cardiovascular Surgery, 67, 568.
Wisheart, J. D. (1970). Coarctation of aorta. Thorax, 25, 347 .

Requests for reprints to: Mrs. Vera Thornton, S 5 Unit Medical Records, Manchester Royal Infirmary, Oxford Road, Manchester. 